\title{
Spatiotemporal evolution of chlorophyll-a concentration from MODIS data inversion in the middle and lower reaches of the Hanjiang River, China
}

\author{
zhuo Chen ${ }^{1}$, ming Dou ${ }^{1}$, Rui Xia ${ }^{2}$, Guiqiu $\mathrm{Li}^{1}$, and Lisha Shen ${ }^{1}$ \\ ${ }^{1}$ Zhengzhou University \\ ${ }^{2}$ Chinese Research Academy of Environmental Sciences
}

May 24, 2021

\begin{abstract}
The global construction of water projects has led to a clear trend of river and lake reservoir formation, spurring increasingly serious ecological environmental deterioration, especially that caused by the frequent occurrence of water blooms. Because of monitoring technology limitations, monitoring the algae content index in water has lagged behind the conventional water quality index, which makes sample monitoring too sparse in many rivers and the monitoring data incoherent, so it cannot truly reflect the evolution of water eutrophication. With moderate resolution imaging spectroradiometer (MODIS) remote sensing data monitoring, continuous chlorophyll-a observation data can be collected effectively. This method has important guiding significance for the early warning and control of water blooms. This study considers the middle and lower reaches of the Hanjiang River in China, based on the current remote sensing communication technology, MODIS remote sensing data, and statistical methods and measured chlorophyll-a concentration correlation analysis. Through the use of the trial and error method to establish the band ratio model and BP neural network model, two types of model errors were compared to determine the optimal algorithm settings for the middle and lower reaches of the Hanjiang River chlorophyll-a inversion. Subsequently, the algorithm model for 2000 to 2011 in the middle and lower reaches of the Hanjiang River chlorophyll-a concentration inversion and the results of the inversion analysis of spatiotemporal evolution characteristics we used to determine the influence of various environmental factors on the chlorophyll-a concentration change.
\end{abstract}

Spatiotemporal evolution of chlorophyll-a concentration from MODIS data inversion in the middle and lower reaches of the Hanjiang River, China

Zhuo Chen ${ }^{1}$, Ming Dou ${ }^{1,2}{ }^{*}$, Rui Xia ${ }^{3, *}$, Guiqiu $\operatorname{Li}^{1,2}$, Lisha Shen ${ }^{1,2}$

1 School of Water Conservancy Science and Engineering, Zhengzhou University, Zhengzhou, 450001, China

2 School of Ecology and Environment, Zhengzhou University, Zhengzhou, 450001, China

3 State Key Laboratory of Environmental Criteria and Risk Assessment, Chinese Research Academy of Environmental Sciences, Beijing, 100012, China

Corresponding Author: Ming Dou E-mail address:dou_ming@163.com

Abstract : The global construction of water projects has led to a clear trend of river and lake reservoir formation, spurring increasingly serious ecological environmental deterioration, especially that caused by the frequent occurrence of water blooms. Because of monitoring technology limitations, monitoring the algae content index in water has lagged behind the conventional water quality index, which makes sample monitoring too sparse in many rivers and the monitoring data incoherent, so it cannot truly reflect the evolution of water eutrophication. With moderate resolution imaging spectroradiometer (MODIS) remote 
sensing data monitoring, continuous chlorophyll-a observation data can be collected effectively. This method has important guiding significance for the early warning and control of water blooms. This study considers the middle and lower reaches of the Hanjiang River in China, based on the current remote sensing communication technology, MODIS remote sensing data, and statistical methods and measured chlorophyll-a concentration correlation analysis. Through the use of the trial and error method to establish the band ratio model and BP neural network model, two types of model errors were compared to determine the optimal algorithm settings for the middle and lower reaches of the Hanjiang River chlorophyll-a inversion. Subsequently, the algorithm model for 2000 to 2011 in the middle and lower reaches of the Hanjiang River chlorophyll-a concentration inversion and the results of the inversion analysis of spatiotemporal evolution characteristics we used to determine the influence of various environmental factors on the chlorophyll-a concentration change.

Keywords: MODIS; chlorophyll-a; algal blooms; Hanjiang River

\section{INTRODUCTION}

Algal blooms are a prominent ecological and environmental problem (Yang et al., 2012), occurring frequently in water bodies worldwide, affecting not only water quality and aquatic organism survival, but also drinking water safety and human life and health in serious cases. A key factor causing this problem is water body eutrophication. A high level of eutrophication in a water body induces blue-green algae to proliferate and form a blue-green algae film on the water surface, thereby polluting the water body. Algal bloom outbreaks usually occur in inland lakes, reservoirs, or ponds (Huo et al., 2019), and outbreaks in large rivers occur only rarely. However, with the construction and operation of water conservancy projects at home and abroad, the hydrological situation of large rivers has transformed. Compared with lakes and reservoirs, their hydrological conditions are more complex and more prone to water blooms, so it is more meaningful to strengthen the monitoring of algal blooms in large rivers and mobile water bodies for water environmental protection.

With the improvement of communication technology, moderate resolution imaging spectroradiometer (MODIS) remote sensing satellite data are widely used in the fields of environmental monitoring, resource investigation, urban planning, and other fields. MODIS is a large space remote sensing instrument (Naghdi et al., 2020) developed by NASA, which provides long-term Earth observation data, including atmospheric information, global coverage, multi-spatial resolution, and multi-spectral images, and can provide support for understanding global climate and the impact of human activities on climate (Liu et al., 2020).

As the main component of chlorophyll in algae, the distribution of chlorophyll-a concentration can better reflect the degree of algal bloom in water bodies (Brigitte, 2019), and there are obvious absorption valleys in the blue band (near $442 \mathrm{~nm}$ ) (Han et al., 1994(a)) and the red band (near $665 \mathrm{~nm}$ ) (Han et al., 1994(b)), and obvious reflection peaks in the infrared band (near $700 \mathrm{~nm}$ ) (Gitelson et al., 1992), showing certain characteristic spectra in water. The high or low concentration of chlorophyll-a leads to a significant change in the reflectance spectral characteristics of a water body (Jiang et al., 2020). Therefore, the indirect estimation of chlorophyll-a concentration from satellite reflectivity data is more dynamic, periodic, and real-time than traditional manual monitoring, which is suitable for inland waters with complex optical characteristics. Furthermore, the inversion model of chlorophyll-a concentration can be used to interpolate the measured chlorophyll-a concentration according to the remote sensing data, which provides support for further studies.

The models often used to invert water quality parameter concentrations from remote sensing data are mostly empirical and semi-empirical models (Shu et al., 2000; Hu et al., 2009; Tebbs et al., 2013; Telesca et al., 2018; Cannizzaro et al., 2019), which have certain shortcomings in inversion accuracy and generalizability and have poor fault-tolerance (Tao et al., 2018). For this reason, some researchers (e.g., Park et al., 2015; Harvey et al., 2015), have continuously improved the inversion accuracy and generalizability by establishing a waveband ratio model and introducing nonlinear relational optimization methods such as neural network methods and genetic algorithms into water quality parameter inversion.

Based on this, this study adopts the band ratio model as well as the BP neural network model, and takes a 
typical river section in the middle and lower reaches of the Hanjiang River in China as the study area. It uses the measured water quality data and MODIS satellite remote sensing data, establishes the band ratio model and BP neural network model through an empirical method, and determines the optimal inversion algorithm for chlorophyll-a in the middle and lower reaches of the Hanjiang River by comparing model errors. The chlorophyll-a concentrations in the middle and lower reaches of the Hanjiang River from 2000 to 2011 were inverted using this model, and the temporal and spatial characteristics of chlorophyll-a concentration in the water body were analyzed.

\section{MATERIALS AND METHODS}

\subsection{Study area}

The Hanjiang River $\left(106^{\circ} 12^{\prime} \mathrm{E}-114^{\circ} 14^{\prime} \mathrm{E}, 30^{\circ} 08^{\prime} \mathrm{N}-34^{\circ} 11^{\prime} \mathrm{N}\right)$ is a tributary of the Yangtze River in China, with a total length of $1577 \mathrm{~km}$ and a drainage area of $15.9 \times 104 \mathrm{~km}^{2}($ Fig. 1$)$. The main stream of the Hanjiang River is $652 \mathrm{~km}$, and the total drainage area of Hubei Province is $4.6 \times 104 \mathrm{~km}^{2}$, flowing through Shiyan, Xiangyang, Jingmen, Xiaogan, Wuhan City, and other cities. The regional economy is developed, and it is an important grain production base in China as well as a new industrial and automobile industrial base in Hubei Province (Kuman et al., 2014).

[Insert Fig. 1. here]

As the largest tributary of the Yangtze River and an important water source for the Middle Route Project of the South-to-North Water Transfer, the water quality of the middle and lower reaches of the Hanjiang River has gradually deteriorated since the 1990s. The main reason is that nutrients, such as nitrogen and phosphorus in the water body, exceed the standard (Stephen et al., 2016; Cheng et al., 2019), resulting in a high degree of eutrophication in the water body, and repeated outbreaks of water blooms, during which the water body appears brown and emits a fishy and pungent odor (Fig. 2 ). Water blooms in the Hanjiang River occur mostly during the dry period (February to March) in late winter and early spring, and the duration varies from half a month to one month. According to incomplete statistics (Xin et al., 2019; Chen et al., 2007; Lu et al., 2000) of various studies (Table 1 ), the water bloom frequency in the Hanjiang River increased after 2000, with diatom blooms dominating in the Hanjiang River (Kuang et al., 2000). Previous studies have mostly considered the dominant species to be Chlorella (Liang et al., 2012), with occasional cases of green algae as the dominant species. However, according to a different study (Zheng et al., 2009; Yin et al., 2011), the dominant species of the Hanjiang water bloom belongs to the genus Corynebacterium. The rapid growth of algae is accompanied by an increase in chlorophyll-a concentration, so it is meaningful to reveal the phenomenon of water blooms in the middle and lower Hanjiang River by studying the change in chlorophyll-a concentration in the middle and lower Hanjiang River.

[Insert Fig. 2. here]

[Insert Table 1. here]

Meanwhile, the transfer of water from the South-North Water Transfer Project has transformed the hydrological situation in the middle and lower reaches of the Hanjiang River, and has tended to aggravate the phenomenon of water blooms (Kuo et al., 2018; Zhou et al., 2017). According to Dou and Xie et al. (Xie et al., 2004; Xie et al., 2005), the impact of the South-North Water Transfer Project on water blooms in the middle and lower reaches of the Hanjiang River is mainly reflected in hydrological factors such as flow rate and velocity. Therefore, it is important to analyze the effects of hydrological factors (including flow rate and velocity) on the changes in chlorophyll-a concentration in the middle and lower reaches of the Hanjiang River to reveal the mechanism of hydrological factors affecting water blooms in the Hanjiang River and to study the water bloom conditions in eutrophic rivers. 


\subsection{Actual data and MODIS data acquisition}

The measured data in the study include two parts: one is the water quality data, including chlorophyll-a concentrations monitored along three cross-sections, Baihezui, Qinguankou, and Zongguan (monitored in February, March, April, September, and October from 2009 to 2013, and monitored three times a month), and total nitrogen (TN) and total phosphorus (TP) concentrations monitored at the Zongguan cross-section (monitored from 2003 to 2009). The second part is the hydrological data, which includes the flow, water level, flow rate, and water temperature data monitored in the Xiantao and Zongguan sections, from 2000 to 2011 (the above data are from the Chinese Research Academy of Environmental Sciences).

The MODIS remote sensing satellite has seven spectral bands from 469 to $2130 \mathrm{~nm}$ with a spatial resolution of $500 \mathrm{~m}$. Several (75) MODIS remote sensing images synchronized with the measured water quality data from 2009 to 2013 were selected, and 64 valid remote sensing images, accounting for $85.33 \%$ of the total images, were filtered after rejection (NASA).

\subsection{MODIS data preprocessing}

The remote-sensing images were preprocessed using ENVI5.3 software (from Exelis Visual Information Solutions Company). Geometric correction was first performed to reduce geometric distortion error. The ENVI automatic orthorectification tool RPC Orthorectification Workflow (Guo, 2002) was used for orthorectification of remote sensing images.

After geometric correction, the MODIS data saved the (Digital Number)DN value, whereas the chlorophyll-a concentration inversion used absolute radiation brightness and reflectivity. For follow-up studies, the DN value needs to be converted to absolute radiance brightness and reflectance, a step called radiometric calibration, which is calculated in ENVI according to Eqns. (1) and (2) (Lv et al., 2009; Carol et al., 2006).

To obtain the reflectance of ground objects more accurately (Feng, 2021; Zheng et al., 2004), it is necessary to correct the atmosphere in the image to eliminate the influence of illumination, water vapor, and other factors on the reflectivity spectrum of ground objects. The FLAASH atmospheric correction module in ENVI was used to correct the images.

The normalized difference water index (NDWI) (Gao, 1996; Choung et al., 2016) was adopted for extraction in the studied water areas. Compared with the traditional normalized difference vegetation index (NDVI) method, NDWI is less sensitive to atmospheric influence, less affected by the atmosphere, and more accurate for water extraction. The formula for calculating the NDWI is as follows (3):

The reflectivity is green light reflectivity and near-infrared reflectivity.

\subsection{MODIS data and chlorophyll-a concentration inversion method}

Chlorophyll-a concentration has a significant effect on the spectral characteristics of water bodies and can be used to establish a link with the spectral characteristics of remote sensing images on this basis (Le et al., 2010; Darecki et al., 2003). The empirical method is a chlorophyll-a inversion method that is currently used more often, and the fitted construction models are mainly single-band, band ratio, and neural network models, whose processes are relatively simple and feasible (Chen et al., 2007).

In this study, first the downloaded MODIS data were corrected and processed to extract the band reflectance, and the water quality data of the actual measured water bodies were correlated with the synchronized remote sensing reflectance data, and the reflectance data of the band or the combination of bands with high correlation were screened out and fitted to construct a model (Anatoly, 2008). 


\subsubsection{Band ratio model}

The band ratio model combines the existing bands and selects the combination that is most relevant to the measured data to perform the inversion modeling (Le et al., 2009). According to the correlation analysis, the interference of the atmosphere on electromagnetic waves and the influence of the smooth water surface on microwaves can be reduced by combining wave bands. In this study, from the pre-processed MODIS remote sensing images, the reflectance of seven bands from B1 to B7 was extracted, and then the statistical analysis software SPSS (form BIM Company) was used to combine each band to obtain 73 band combination patterns. There were 21 modes for the division of two bands (B1/B2), 20 modes for subtraction of two bands (B1-B2), 15 modes for three bands (B1/(B2 B3)), 10 modes for four bands (B1/(B2 + B3 + B4)), and seven modes for natural logarithm (ln (B1)). Then, a correlation analysis between the band combination model and the measured concentration of chlorophyll-a was performed, and a function model was established.

\subsubsection{BP neural network model}

The BP neural network method is currently one of the more widely used artificial neural networks, with the characteristics of forward signal propagation and backward error propagation (Le et al., 2000), which has the functions of self-adaptation, self-learning, self-organization, and nonlinear mapping, which are suitable for simulating various intricate nonlinear relationships. It has been proven that a network with deviation and at least one S-shaped implicit layer plus a linear output layer can approximate any rational function (Zhu et al., 2017).

Because of the complex optical properties in the water column and the many factors affecting chlorophyll-a concentration, the relationship between reflectance and chlorophyll-a concentration cannot be accurately reflected using a simple linear model (Feng et al., 2021). According to its characteristics, the BP neural network can better solve the problem of complex nonlinear relationships between reflectance and chlorophylla concentration, as shown in the schematic diagram in Fig. $\mathbf{3}$, where $X_{1}, X_{2}, \ldots X_{n}$ are the input and output values of the BP neural network model. In this study, the combination of the high correlation of wave reflectance with chlorophyll-a concentration can be used as input factors $\left(X_{1}, X_{2}, \ldots, X_{n}\right)$ for the BP neural network input layer, and chlorophyll-a concentration of the BP neural network. The combination of band reflectivity and concentration of chlorophyll-a was used to adjust the weights and thresholds of the network to generate the model.

[Insert Fig.3. here]

\subsection{Model validation method}

To test the model precision and make the inverse model more accurate, this study evaluates model accuracy by the decision coefficient R2, relative error RE, and root-mean-square error RMSE. The formulas are (4), (5), and (6). The predicted value was the measured value.

\section{RESULTS AND ANALYSIS}

Based on the inversion method of MODIS data and chlorophyll-a concentration proposed in Section 2.4, the inversion of chlorophyll-a concentration in the middle and lower reaches of the Hanjiang River was performed, and an analysis of spatial and temporal variation in chlorophyll-a concentration, interannual variation in chlorophyll-a concentration distribution area, and interannual variation in chlorophyll-a concentration values in typical years were conducted based on the inversion results. The specific results and analyses are as follows. 


\subsection{Results of correlation analysis}

The correlation analysis of reflectance with the measured chlorophyll-a concentration values was calculated, as shown in Table $\mathbf{2}$. The B5 reflectance was significantly correlated with the measured chlorophyll-a concentration, and the Pearson correlation coefficient was -0.645 , with a significance of 0.009 . The B2 and B6 bands were significantly correlated with the measured concentration of chlorophyll-a, and the Pearson correlation coefficients were -0.55 and -0.515 , with significance of 0.033 and 0.049 , respectively.

[Insert Table 2. here]

[Insert Table 3. here]

The results of the correlation analysis of 73 combinations of wavelength reflectance and measured chlorophylla concentration values obtained using the rule of four are presented in Table 3. The results showed that the B7/B5, B7-B6, B7-B5, B5-B4, B5-B1, B4-B2, B2-B1, B7/(B6 B5), B4/(B3 + B2), and LN (B5) band combinations showed good correlation, with Pearson correlation coefficients of $0.679,0.610,0.609,-0.621$, $-0.688,0.635,-0.730,0.774,0.646$, and -0.712 , respectively (Table 3 ).

\subsection{Modeling results}

According to the results in Section 3.1, the correlation between the B7/(B6-B5) band combination and the measured chlorophyll-a concentration value was high, and the Pearson correlation coefficient was 0.744 , which is significant. Therefore, the B7/(B6-B5) band reflectance was selected as an independent variable, and the measured chlorophyll-a concentration was a dependent variable. In SPSS software, eleven common function models, including the linear, logarithmic, inverse, quadratic, and cubic function models were selected to construct the model among variables. The calculation results are shown in Fig. 4 and Table 4.

[Insert Fig.4. here]

[Insert Table 4. here]

To select the most suitable model, the coefficient of determination $\mathrm{R}^{2}$ and the significance of the eleven models are calculated in Table 4 , which shows that the cubic function model coefficient of determination $\mathrm{R}^{2}$ is 0.677 , and the significance is 0.001 . Compared with the other ten prediction models, the cubic function model could predict the chlorophyll concentration in the middle and lower reaches of the Hanjiang River most realistically. Therefore, this study chose the cubic model as the inversion model of the wave band ratio, and the calculation formula is as follows (7):

where $\mathrm{y}$ is the prediction value of chlorophyll concentration and $\mathrm{x}$ is $\mathrm{B} 7 /(\mathrm{B} 6-\mathrm{B} 5)$.

In this section, 60 remote sensing images were randomly selected from 64 remote sensing images, which were extracted using ENVI5.3, and the band combination with the highest correlation with the measured chlorophyll-a concentration was selected as the input factor of the BP neural network model input layer according to Table 3, namely B7/(B6+B5), B7/B5, B4-B2, B4/(B3+B2). Whether the BP neural network model can solve the nonlinear problem accurately depends on the number of hidden layer nodes set in the neural network model, and number of nodes that directly affects the mapping ability of the neural network to the nonlinear problem (Chen et al., 2008). In this study, the trial and error method was used to calculate the node number of the final hidden layer. The results are listed in Table $\mathbf{5}$.

According to Table 5 , when the number of nodes is four, the judgment coefficient $\mathrm{R}^{2}$ is 0.98918 , and the RMSE is 3.1462 . The principle of the neural network model shows that the more hidden layer nodes, the more complex the model, and the longer the required training time. Therefore, the number of hidden layer nodes was determined to be four.

[Insert Table 5. here] 
Finally, four waveband combinations of B7/(B6-B5), B7/B5, B4-B2, and B4/(B3 + B2) were used as input factors for the BP neural network. The hidden layer was identified as a single layer, and the node number of the hidden layer was set to four according to Table $\mathbf{3}$. The hidden layer transfer function was an Sshaped hyperbolic tangent function, and the output layer was the measured chlorophyll-a concentration value synchronized with the waveband combination. The maximum training time was set to 1000, and the learning rate was set to 0.001 of 60 actual samples, 55 samples were selected randomly for training, and the remaining five samples were used as test samples.

\section{[Insert Fig5. here]}

As shown in Fig. 5, when using the BP neural network model, the judging coefficient $\mathrm{R}^{2}$ is 0.98918 , the RMSE is 3.1462 , the $\mathrm{RE}$ is $29.1 \%$, the minimum is $8 \%$, the average $\mathrm{RE}$ is $21.4 \%$, and the simulation forecasting effect is poor. Therefore, the BP neural network model predicted less error than the band ratio model, indicating that the inversion of chlorophyll-a concentrations in the middle and lower reaches of the Hanjiang River was more accurate using the BP neural network model. Additionally, the study confirmed that the BP neural network model was more suitable for simulating nonlinear problems arising from the complex optical properties in water bodies.

\subsection{Spatiotemporal variation analysis of typical annual chlorophyll-a concentra- tion}

The investigation shows that the eruption of water blooms in 2000 and 2008 lasted from late February to mid-March and from late January to early March, respectively. In this study, the chlorophyll-a concentration in the middle and lower reaches of the Hanjiang River during the bloom eruption period in 2000 and 2008 was inverted from the remote sensing image data of MODIS on February 24, March 4, and March 12 of 2000 and January 2, January 17, February 3, February 14, March 7, and March 14 of 2008 and the trend in the bloom area was analyzed. When the concentration of chlorophyll-a was $0-10 \mu \mathrm{g} / \mathrm{L}$, the water quality was better. When the concentration of chlorophyll-a was $10-25 \mu \mathrm{g} / \mathrm{L}$, there was no obvious bloom; when the concentration of chlorophyll-a was $25-35 \mu \mathrm{g} / \mathrm{L}$, there was a bloom; and when the concentration of chlorophyll-a was $>35 \mu \mathrm{g} / \mathrm{L}$, there was a severe bloom.

From Fig. 6 , it can be seen that on February 24, 2000, the total concentration of chlorophyll-a in the middle and lower reaches of the Hanjiang River was relatively high, the concentration of chlorophyll-a in the area near the monitoring section of the Yuekou River was $>25 \mu \mathrm{g} / \mathrm{L}$ in a wide banded distribution, and the concentration of chlorophyll-a in the area $<10 \mu \mathrm{g} / \mathrm{L}$ was mainly distributed in the area near Zhongxiang City and the lower reaches of Shayang County. On March 4, 2000, the overall chlorophyll-a concentration in the middle and lower reaches of the Hanjiang River continued to increase, and the areas with chlorophyll-a concentrations $>35 \mu \mathrm{g} / \mathrm{L}$ were distributed throughout the study area and were more widely distributed in the upper reaches of Xiantao City and near Shayang County, showing a band-like distribution, while the rest were scattered along both riverbanks. Compared with February 24 and March 4, the water bloom outbreak area increased significantly, spreading from Zhongxiang to Shayang, Yuekou to Xiantao, and gradually spreading to the center of the river channel from the shore. The concentration of chlorophyll-a was $>35 \mu \mathrm{g} / \mathrm{L}$ in the lower reaches of Shayang County and the upper reaches of Yuekou Town, and it was distributed in blocks along the west bank. Chlorophyll-a concentration decreased downstream of Yuekou Town and upstream of Xiantao City, and the water bloom phenomenon improved and the water bloom migrated to the vicinity of Shayang County.

[Insert Fig6. here]

Fig. 7 shows that from January 2 to January 17 in 2008, the overall chlorophyll-a concentration in the study area was not high. On the 3rd, the concentration of chlorophyll-a in the downstream water body area of Zhongxiang City was relatively high. The $10 \mu \mathrm{g} / \mathrm{L}$ to $25 \mu \mathrm{g} / \mathrm{L}$ chlorophyll-a concentration area was distributed in a band from Zhongxiang City to Shayang County. On February 14, 2008, the entire middle and lower reaches of the Hanjiang River, the lower reaches of Zhongxiang City, and some waters near Yuekou 
Town had chlorophyll-a concentrations $<10 \mu \mathrm{g} / \mathrm{L}$. Near Shayang County, the chlorophyll-a concentrations were higher. If concentrations are $>35 \mu \mathrm{g} / \mathrm{L}$, it indicates that the water body is highly eutrophic, and serious blooms are likely. On March 7, 2008, the concentration of chlorophyll-a in the study area was > $35 \mu \mathrm{g} / \mathrm{L}$, and was more evenly distributed throughout the study area, mostly concentrated on the shore. The areas where the chlorophyll-a concentration was $>25 \mu \mathrm{g} / \mathrm{L}$ near the upper reaches of Zhongxiang City and Shayang County were denser, and water blooms appeared from Zhongxiang City and Shayang County. On March 14, 2008, the area of chlorophyll-a concentration $<10 \mu \mathrm{g} / \mathrm{L}$ began to gradually increase, the areas with chlorophyll-a concentration $>35 \mu \mathrm{g} / \mathrm{L}$ also decreased, and the water bloom showed an overall dissipating trend.

[Insert Fig7. here]

\subsection{Analysis of interannual variation in chlorophyll-a concentration distribution area}

A preliminary investigation found that water blooms occur in the middle and lower reaches of the Hanjiang River in February and March each year (Yang et al., 2012; Zhu et al., 2008). To study the variation in chlorophyll-a concentration in the middle and lower reaches of the Hanjiang River during the bloom period, this section reverses the chlorophyll-a concentration distribution during the bloom period from 2000 to 2011 (from February to March). As shown in Fig. 8, the chlorophyll-a concentration distribution accounts for the results inFig. 9 .

As can be seen from Fig. 8 and Fig. 9 , the areas with chlorophyll-a concentrations $<10 \mu \mathrm{g} / \mathrm{L}$ were relatively high in 2001, 2004, 2005, and 2009, accounting for $78.3 \%, 82.4 \%, 64.3 \%$, and $75.8 \%$, respectively, indicating that the chlorophyll-a concentration in most waters remained low at this time, the water quality was generally good, and the risk of bloom outbreaks was relatively low. The trend line in Fig. 9 (1) shows that the area ratio with chlorophyll-a concentration $<10 \mu \mathrm{g} / \mathrm{L}$ fluctuated between 2000 and 2011, but there was a slight downward trend overall, indicating that the water quality in the middle and lower reaches of the Hanjiang River gradually improved during this period. In 2000, 2006, 2007, and 2008, the concentrations of chlorophyll-a $>25 \mu \mathrm{g} / \mathrm{L}$ were $57.9 \%, 70.2 \%, 49.3 \%$, and $50.10 \%$, respectively, indicating that the concentration of chlorophyll-a was high, eutrophication was high, water quality was poor, and water bloom outbreaks occurred easily or had already occurred. The area ratio of chlorophyll-a $>25 \mu \mathrm{g} / \mathrm{L}$ remained stable and low from 2001 to 2005, and remained stable but high from 2006 to 2008, compared with the area ratio of chlorophyll-a $<10 \mu \mathrm{g} / \mathrm{L}$. According to the trend line, the chlorophyll-a concentration area ratio remained stable from 2000 to 2011 during the bloom-prone period.

[Insert Fig8. here]

[Insert Fig9. here]

\subsection{Interannual variation analysis of chlorophyll-a concentration value}

To better reflect the interannual variation in chlorophyll-a concentration values, this section inverts the chlorophyll-a concentration values of five monitoring sections (Huangzhuang, Shayang, Yuekou, Xiantao, and Zongguan) between 2000 and 2011, and analyzes the interannual variation based on the inversion results. The results are shown in Fig. 10, and the statistical results are presented inTable 6 .

[Insert Fig10. here]

[Insert Table 6. here]

According to the statistical results, during the twelve years from 2000 to 2011, the highest chlorophyll-a concentration was $41.837 \mu \mathrm{g} / \mathrm{L}$ in February 2008 at the Shayang monitoring section, and the lowest chlorophyll-a concentration was $2.774 \mu \mathrm{g} / \mathrm{L}$ in October 2001 at the Huangzhuang monitoring section. From the average chlorophyll-a concentrations in each of the twelve years, the chlorophyll-a concentrations in 2000, 2006, and 
2008 were higher than those in other years, which is consistent with the historical data showing the years with water blooms, and the chlorophyll-a concentrations gradually increased. From the average chlorophyll-a concentrations in each of the twelve years, the chlorophyll-a concentrations were higher in 2000, 2006, and 2008 than in other years, which is consistent with the historical data showing the years with water bloom outbreaks. Furthermore, the chlorophyll-a concentration gradually increased between 2001 and 2004, indicating that the algae in the middle and lower reaches of the Hanjiang River increased during this period, the eutrophication of the water body increased, and the water quality deteriorated. Among the statistical data, chlorophyll-a concentrations exceeding $30 \mu \mathrm{g} / \mathrm{L}$ occurred fourteen times, including three times in 2000, four times in 2006, and three times in 2008, and less frequently in the remaining years. Based on the analysis of the interannual chlorophyll-a concentration values at each monitoring section, the monthly average chlorophyll-a concentration values $>30 \mu \mathrm{g} / \mathrm{L}$ at Huangzhuang, Shayang, Yuekou, Xiantao, and Zongguan monitoring sections were three, five, two, four, and two times from 2000 to 2011, respectively, indicating that the probability of occurrence of water bloom in the Shayang and Xiantao river sections was higher than that in other river sections, and was predominantly concentrated in spring.

\section{DISCUSSION}

Algal bloom outbreaks refer to the phenomenon of excessive reproduction and aggregation of algae formed under certain nutrition, climate, hydrological conditions, and ecological environments (Le et al., 2017). The outbreak of algal blooms is an ecological problem that depends not only on the nutrient conditions of algal growth, but also on the ecological environment in which the algae grow. Meanwhile, algal blooms also depend on the relationship between algae and other aquatic organisms and the ecological environment, such as changes in hydrological and meteorological conditions that affect these ecological relationships. In this section, the effects of environmental factors on algal blooms are discussed by analyzing the effects of environmental factors on chlorophyll-a concentration.

\subsection{Effect of water temperature on concentration of chlorophyll-a}

Most studies show that most water blooms in the Hanjiang River are diatom blooms (Xu et al., 2005). When the temperature was $>9{ }^{\circ} \mathrm{C}$, the growth of diatoms became active, and grew well between $15{ }^{\circ} \mathrm{C}$ and $35{ }^{\circ} \mathrm{C}$, but the optimal temperature range was $10{ }^{\circ} \mathrm{C}$ to $17^{\circ} \mathrm{C}$, which was beneficial to the cell division and pigment accumulation of diatomaceous bloom algae (Zheng, 2005); therefore, the concentration of chlorophyll-a, an indicator of algae, was higher. Taking Xiantao as an example, from February 2000 to March 2008, the average measured water temperatures were $11.5{ }^{\circ} \mathrm{C}$ and $12{ }^{\circ} \mathrm{C}$, respectively, but no bloom occurred in 2009 and 2010 , at $9{ }^{\circ} \mathrm{C}$ and $10{ }^{\circ} \mathrm{C}$, respectively. In contrast, the water temperature in the bloom eruption period was approximately $2{ }^{\circ} \mathrm{C}$ higher. Water temperature is one of the factors affecting chlorophyll-a concentration.

\subsection{Effect of hydrological conditions on chlorophyll-a concentration}

Hydrological conditions include water level, discharge, and velocity; when blooms occur, the water level, discharge, and velocity of the middle and lower reaches of the Hanjiang River are significantly lower than those of the same period in previous years (Wang et al., 2004). Bloom outbreaks in the Hanjiang River generally occur in the early spring of February to March each year, which is the Hanjiang River dry season when the water level is low and has good transparency. At this time, bloom diatoms can make full use of sunlight for photosynthesis and accumulate photosynthetic products, thereby facilitating cell division and proliferation and causing an increase in chlorophyll-a concentration (Tang et al., 2001). According to the measured data, the average water level of at the hydrometric station in 2000, 2003, and 2008 was $23.71 \mathrm{~m}$ and the average flow rate was $474.3 \mathrm{~m} / \mathrm{s}$, which was $1.67 \mathrm{~m}$ lower and the average flow rate was $55.43 \%$ lower than that in 2001, 2004, and 2005. The flow rates of the Zongguan sections in 2000, 2003, 2006, and March 2008 were $0.168 \mathrm{~m} / \mathrm{s}, 0.166 \mathrm{~m} / \mathrm{s}, 0.267 \mathrm{~m} / \mathrm{s}, 0.230 \mathrm{~m} / \mathrm{s}$, respectively, and the average flow rate was 
$0.208 \mathrm{~m} / \mathrm{s}$, according to the flow data and the flow rate calculated from the cross-sectional area of the diatom bloom. In contrast, the average velocity of the Zongguan section from January to March was $0.289 \mathrm{~m} / \mathrm{s}$, and the average velocity of the Zongguan section decreased by $28.02 \%$. As can be seen from Fig. 11 at higher chlorophyll-a concentrations, the discharge is smaller and the water level is lower. Therefore, the variation in chlorophyll-a concentration is affected by hydrological factors such as water level, discharge, and velocity.

[Insert Fig.11. here]

[Insert Table 7. here]

[Insert Table 8. here]

\subsection{Effect of nutrient on chlorophyll-a concentration}

Nitrogen and phosphorus are the main nutrients required for phytoplankton reproduction and growth (Lin et al., 2021; Liu et al., 2021). Because of the large variation in chlorophyll-a concentration values in the middle and lower reaches of the Hanjiang River from 2003 to 2009, the chlorophyll-a concentration values from the inverse performance of the Zongguan monitoring section in this section were compared with the measured total nitrogen and total phosphorus values, and the results are shown in Fig. 12 . It was found that the variation in chlorophyll-a concentration was similar to that of nitrogen and phosphorus in all years except 2005, that is, the increase in chlorophyll-a concentration values was accompanied by an increase in nitrogen and phosphorus concentrations. This shows that the nitrogen and phosphorus content in the water column during the water bloom could meet the needs of the proliferation of diatoms in the Hanjiang River water bloom, and with the increase in nitrogen and phosphorus concentrations, the diatom growth trend improved, which increased the chlorophyll-a concentration in the water column. However, numerous studies (Luo et al., 2021; Jing et al., 2019; Guenther et al., 2015) have also shown that high concentrations of nitrogen or phosphorus may lead to uncoordinated nitrogen-phosphorus ratios in the water column, thus affecting the growth of diatoms in the water. Therefore, the variation in nitrogen and phosphorus nutrient concentrations and the ratio of nitrogen and phosphorus nutrients are the main factors affecting the variation in chlorophyll-a concentration.

[Insert Fig.12. here]

\section{CONCLUSIONS}

Based on the results of the correlation analysis, the BP neural network model was used to invert the chlorophyll-a concentration in the middle and lower reaches of the Hanjiang River in 2000-2011. The typical annual chlorophyll-a concentration distribution map of bloom outbreaks in the middle and lower reaches of the Hanjiang River was used to analyze the bloom outbreak process. According to the calculation results of the percentage of chlorophyll-a concentration distribution in the middle and lower reaches of the Hanjiang River during the bloom period from 2000 to 2011, the area with chlorophyll-a concentration < $10 \mu \mathrm{g} / \mathrm{L}$ was relatively high in 2001, 2004, 2005, and 2009, the concentration of chlorophyll-a in most waters was relatively low, and the water quality was relatively good. The area with chlorophyll-a concentration $>25 \mu \mathrm{g} / \mathrm{L}$ was relatively high in 2000, 2006, 2007, and 2008, and the concentration of chlorophyll-a in most waters was relatively high, eutrophication was relatively high, and water quality was generally poor. By analyzing the influence of environmental factors on the concentration of chlorophyll-a, the water temperature and hydrological conditions, including water level, flow rate, and concentration and ratio of nutrients, including nitrogen and phosphorus, were established as the main factors leading to an increase in chlorophyll-a concentration in the middle and lower reaches of the Hanjiang River. 


\section{ACKNOWLEDGEMENTS}

Funding: This work was supported by the National Natural Science Foundation of China [grant numbers 51879239, 51879252], and the Program for key Science \& Technology projects in Universities of Henan Province [No. 21A570008].

\section{DATA AVAILABILITY}

Data is not shared publicly

\section{REFERENCES}

Anatoly, A. (2008). A simple semi-analytical model for remote estimation of chlorophyll-a in turbidwaters: Validation. Remote Sensing of Environment , 112, 3582-3593.

Brigitte, V.L. (2019). Catherine Celine Eutrophication Modeling of Lake Ecosystems: A Review. Science of The Total Environment, 651 (Pt 2), 2985-3001.

Bruegge, C.J., Diner D.J., Kahn, R.A., Chrien, M., Helmlinger, M.C., Gaitley, B.J., Abdou, W.A. (2006). The MISR radiometric calibration process. Remote Sensing of Environment , 107(1), 2-11.

Cannizzaro, J.P., Barnes, B.B., Hu, C.M., Corcoran, A.A., Hubbard, K.A., Muhlbach, E., Sharp, W.C., Brand, L.E., Kelble, C.R. (2019). Remote detection of cyanobacteria blooms in an optically shallow subtropical lagoonal estuary using MODIS data. Remote Sensing of Environment, 231.

Chen, C.Q., Tang, S.L., Pan, Z.L., Zhan, H.G., Larson, M., Jönsson, L. (2007). Remotely sensed assessment of water quality levels in the Pearl River Estuary, China. Marine Pollution Bulletin, 54(8), 1267-1272.

Chen, H., Guo, S.L., Xu, C.Y., Singh, V.P. (2007). Historical temporal trends of hydro-climatic variables and runoff response to climate variability and their relevance in water resource management in the Hanjiang basin. Journal of Hydrology , 344(3), 171-184.

Chen, H.Y., Wang, Z.X., Gao, C.Y., Qin, J., Yao, F.B., Xu, W. (2008). Determining the number of BP neural network hidden layer unist. Journal of Tianjin University of Techonlogy , (05), 13-15.

Cheng, B.F., Xia, R., Zhang, Y., Yang, Z.W., Hu, S., Guo, F., Ma, S.Q. (2019). Characterization and causes analysis for algae blooms in large river system. Sustainable Cities and Society . 51.

Choung, Y.J., Jo, M.H. (2016). Monitoring Water Resource Changes Using Multi-temporal Landsat Imagery Taken in Changnyeong, South Korea.Procedia Engineering . 154, 348-352.

Darecki, M., Weeks, A., Sagan, S., Kowalczuk, P., Kaczmarek, S. (2003). Optical characteristics of two contrasting Case 2 waters and their influence on remote sensing algorithms. Continental Shelf Research, 23(3), 237-250.

Feng, C.,Zhao, N.J.,Yin, G.F.,Gan, T.T.,Yang, T.T.,Chen, X.W.,Chen, M,Duan, J.B. (2021). Artificial neural networks combined multi-wavelength transmission spectrum feature extraction for sensitive identification of waterborne bacteria. Spectrochimica Acta Part A: Molecular and Biomolecular Spectroscopy . 251.

Feng, L. (2021). Key issues in detecting lacustrine cyanobacterial bloom using satellite remote sensing. Lake Science, $33(3)$.

Gao, B.C. (1996). NDWI-A normalized difference water index for remote sensing of vegetation liquid water from space. Remote Sensing of Environment , 58(3), 257-266. 
Gitelson, A., et al. (1992). The peak near700nmon radiance spectra of al-gae andwater: relationshipsof itsmagnitude and positionwith chloro-phyll concentration. International Journal of Remote Sensing , 13, 3367-3373.

Guenther, M., Araújo, M., Flores-Montes, M., Gonzalez-Rodriguez, E., Neumann-Leitão, S. (2015). Eutrophication effects on phytoplankton size-fractioned biomass and production at a tropical estuary. Marine Pollution Bulletin , 91(2), 537-547.

Guo, G.M. (2002). Geometric Calibration of MODIS Data. Remote sensing information , (03). 26-28

Han, L. (1994). The response of both surface reflectance and the un-derwater light field to various levels of suspended sediments: prelimi-nary results. Photogrammetric Engineering and Remote Sensing , 60(12), 1463-1471.

Han, L., Rundquist, D. C., Liu, L. L., Fraser, R. N., Schalles, J. F. (1994). The spectral responses of algal chlorophyll a in water with varying levels of suspended sediment. International Journal of Remote Sensing , 15(18), 3707-3718.

Harvey,E.T., Kratzer, S., Philipson, P. (2015). Satellite-based water quality monitoring for improved spatial and temporal retrieval of chlorophyll-a in coastal waters. Remote Sensing of Environment , 158, 417-430.

Hu, Z.Y., Yu, H.Y., Zhou, B. (2009). MODIS band ratio algorithm about cyanobacteria bloom in Taihu Lake applied in emergent monitoring. Wetland Science , 7(02), 169-174.

Huo, S.L., He, Z.S., Ma, C.Z., Zhang, Z.X., Xi, B.D., Zhang, J.T., Li, X.C., Wu, F.C., Liu, H.L. (2019). Spatiotemporal impacts of meteorological and geographic factors on the availability of nitrogen and phosphorus to algae in Chinese lakes. Journal of Hydrology , 572, 380-387.

Jiang, G.J., Steven, A.L., Yang, D.T., Ma, R.H., Su, W., Gao, C.J. (2020). Remote estimation of chlorophyll a concentrations over a wide range of optical conditions based on water classification from VIIRS observations. Remote Sensing of Environment, 241, 111735.

Jing, Z.X., Xia, J., Zhang, X., Wang, Q., Shi, W., Ma, X.Y. (2019). Spatial and Temporal Distribution and Variation of Water Quality in the Middle and Downstream of Hanjiang River. Research of Environmental Sciences , 32(01), 104-115.

Kuang, Q.J., Tan, Y.Y., Wan, D.B., Zhang, J.Y. (2000).On the phytoplankton in the middle and lower reachesof the Hangjiang River and the prevention of water-blooms. Resources and Environment in the Yangtze Basin , 9(01). 63-70.

Kuman, K, Li, C.R., Li, H. (2014). Large cutting tools in the Danjiangkou Reservoir Region, Central China. Journal of HumanEvolution , 76, 129-153.

Kuo, Y.M., Liu, W.W., Zhao, E.M., Li, R., Yao, L.Q. (2018). Rafael Munoz-Carpena. Water quality variability in the middle and down streams of Hanjiang River under the influence of the Middle Route of South-North Water Diversion Project, China. Journal of Hydrology , 569.

Le, C.F., Li, Y.M., Zha, Y., Sun, D.Y., Huang, C.C., Zhang, H. (2010). Remote estimation of chlorophyll a in optically complex waters based on optical classification. Remote Sensing of Environment, 115(2), 725-737.

Le, C.F., Li, Y.M., Zha, Y., Sun,D.Y., Huang, C.C., Lu, H. (2009). A four-band semi-analytical model for estimating chlorophyll-a in highly turbid lakes: The case of Taihu Lake, China. Remote Sensing of Environment , 113(6), 1175-1189.

Li W., Wang, X.Y., Jin, X.B., Xu, J.P., Zhang, H.Y., Yu, J.B., Sun, Q., Gao, C., Wang, L.B. (2017). Analysis of algae growth mechanism and water bloom prediction under the effect of multi-affecting factor. Saudi Journal of Biological Sciences, 24(3). 
Li, X.F., Liu, G.Z. (2000). The Improvement of BP Algorithm and Its Applicatio.Journal of Sichuan University, (02), 105-109.

Liang, K.X., Wang, X.Y., Zhang, D.B., Zhou, Y.H. (2012). Ecological conditions of diatomwater bloomformulation in the middle and lower reach of the Hanjiang River and strategy for water bloom control.Environmental Science And Technology, 35(12J), 113- 116.

Lin, S.S., Shen, S.L., Zhou, A.N., Lyu, H.M. (2021). Assessment and management of lake eutrophication: A case study in Lake Erhai, China.Science of The Total Environment . 751, 141681.

Liu, B., Chen, S., Liu, H., Guan, Y.Q. (2020). Changes in the ratio of benthic to planktonic diatoms to eutrophication status of Muskegon Lake through time: Implications for a valuable indicator on water quality.Ecological Indicators, 114.

Liu, Q., Cheng, N., He Q., Chen, H.Y., Liu, T.Q., Liu, X., Zhang, H., Li, J.Z., Zhan, Q.U. (2019). Meteorological conditions and their effects on the relationship between aerosol optical depth and macro-physical properties of warm clouds over Shanghai based on MODIS.Atmospheric Pollution Research , 11(9), 16371644 .

Lu, D.Y., Liu, P.G., Fan, T.Y., Peng, H., Zhang, Z.K. (2000). Investigation and study of the sudden "water bloom" in the lower reaches of the Hanjiang River. Research of Environmental Sciences , 13(02), 28-31.

Luo, D., Zheng, L., Zhang, Z., Li, M., Chen, Z.W., Cui, R.G., Shen, Y.B., Li, G.R., Feng, R.F., Zhang, S.J., Jiang, G.P., Chen, L.W., Yu, A.P., Wang, X. (2021). Constructing multifunctional solid electrolyte interface via in-situ polymerization for dendrite-free and low N/P ratio lithium metal batteries.Nature Communications , 12(1).

Lv, H., Huang, J.H., Jiang, N. (2009). Quantitative retrieval of water quality by remote sensing in Taihu Lake based on MODIS data.Journal of Geo-Information Science, 11(01), 104-110.

Naghdi, K., Moradi, M., Rahimzadegan, M., Kabiri, K., Rowshan Tabari, M. (2020). Quantitative modeling of cyanobacterial concentration using MODIS imagery in the Southern Caspian Sea. Journal of Great Lakes Research , 46(5), 1251-1261.

Park, Y.G., Cho, K.H., Park, J.H., Cha, S.M., Kim, J.H., 2015. Development of early-warning protocol for predicting chlorophyll-a concentration using machine learning models in freshwater and estuarine reservoirs, Korea. Science of The Total Environment. 502, 31-41.

Powers, S.M., Bruulsema, T.W., Burt, T.P., Chan, N.I., Elser, J.J., Haygarth,P.M., Howden,N.J.K., Jarvie,H.P., Lyu, Y., Peterson, H.M., Sharpley, A.N., Shen, J.B. (2016). Fred Worrall,Fusuo Zhang. Longterm accumulation and transport of anthropogenic phosphorus in three river basins. Nature Geoscience, 9(5), 353-365.

Shu, X.Z., Wang, J.F., Shen, M.M., Kuang, D.B. (2000). Remote sensing of water quality monitoring using an airborne imaging spectprmeter. Journal of Infrared and Millimeter Waves , (04), 273-276.

Tang, Y.R., Wang, G.R. (2001). HanJiang River" algae bloom" Cause Analysis and Prevention. Chongqing Environmental Science, (05), 21-23.

Tao, R., Peng, J.C., Zhang, H., Wu, Y.X., Zhang, D.R. (2018). A review of remote sensing retrieval models of chlorophyll-a concentration in inland water bodies. Private Technology , (12), 97-98.

Tebbs, E.J., Remedios, J.J., Harper, D.M. (2013). Remote sensing of chlorophyll- a as a measure of cyanobacterial biomass in Lake Bogoria, a hypertrophic, saline-alkaline, flamingo lake, using Landsat ETM.Remote Sensing of Environment, 135, 92-106.

Telesca, L., Pierini, J.O., Lovallo, M., Santamaria-del-Angel, E. (2018). Spatio-temporal variability in the Brazil-Malvinas Confluence Zone (BMCZ), based on spectroradiometric MODIS-AQUA chlorophyll-a observations. Oceanologia, 60(1), 76-85. 
Wang, H.P., Xia, J., Xie, P., Dou, M. (2004). Mechanisms for hudrological factors causing algal blooms in Hangjiang River-Based onkinetics of algaegrowth. Resources and Environment in the Yangtze Basin, (03), 282-285.

Xie, P., Dou, M., Xia, J. (2005). Different Schemes of the Water Transfer on the Water Bloom in the Middle and Lower Reaches of the Hangjiang River. South-to-North Water Transfer and Water Science and Technology, 3(01), 7-9.

Xie, P., Xia, J., Dou, M. (2004). Reasearch into the effects of the middle route of China's south-to-north water transferproject on water bloom in the middle-down srream of Hanjiang River and the countermeasures Part I:An analysis of the key fators generating water bloom in Hanjiang River. Journal of natural resources , (04), 418-423.

Xin, X.K., Zhang, H., Lei, P., Tang, W.Z., Yin, W., Li, J., Zhong, H., Li, K.F. (2020). Algal blooms in the middle and lower Hanjiang River: Characteristics, early warning and prevention. Science of the Total Environment, 706 .

Xu, L., Xu, S.Q., Sun, F., Chen, W.G. (2005). Dynamic monitoring and water quality evaluation of planktonic algae in Wuhan section of Hanjiang River. Cheinese Journal of Health laboratory technology , (11), $74-75$.

Yang, Q., Xie, P., Shen, H., Xu, J, Wang, P.L., Zhang, B. (2012). A novel flushing strategy for diatom bloom prevention in the lower-middle Hanjiang River. Water Research , 46(8).

Yang, Q., Xie, P.,Shen, H., Xu, J., Wang, P.L., Zhang, B. (2012). A novel flushing strategy for diatom bloom prevention in the lower-middle Hanjiang River. Water Research , 46(8), 2525-2534.

Zhou, Y.L., Zhou, Y.L., Guo, S.L., Hong, S.J., Chang, F.J. (2017). Systematic impact assessment on inter-basin water transfer projects of the Hanjiang River Basin in China. Elsevier, 553, 584-595.

Yin, D.C., Zheng, L.L., Song, L.R. (2011). Stephanodiscus hantzschii bloom in The Hangjiang River:SpatioTemporal distribution and possible driving forces. Resources and Environment in the Yangtze Basin, 20(04), 451-458.

Zheng, L.L. (2005). The physiological and ecological research about the dominant species in Hangjiang River ditom bloom, M.A. Thesis. Fuzhou: Fujian Normal University.

Zheng, L.L., Song, L.R., Wu, X.H., Zhuang, H.R. (2009). Analysis of morphology and 18SrDNA gene from the causative specie related diatom bloom in Hangjiang River. ACTA hydrobiologica sinca , 31(03), 562-565.

Zheng, W., Zeng, Z.Y. (2004). A Review on Methods of Atmospheric Correction for Remote Sensing Images. Remote sensing information, (04), 66-70.

Zhu, Y.F., Zhu, L., Li, J.G., Chen, Y.J., Zhang, Y.H., Hou, H.Q., Ju, X.,Zhang, Y.Z. (2017). The study of inversion of chlorophyll a in Taihu based on GF-1 WFV image and BP neural network. Acta Scientiae Circumstantiae, 37(01), 130-137.

Zhu, Y.P., Zhang, H.P., Chen, L., Zhao, J.F. (2008). Influence of the South-North Water Diversion Project and the mitigation projects on the water quality of Hanjiang River. Science of the Total Environment, 406(1).

\section{Hosted file}

Table.docx available at https://authorea.com/users/415405/articles/523286-spatiotemporalevolution-of-chlorophyll-a-concentration-from-modis-data-inversion-in-the-middle-andlower-reaches-of-the-hanjiang-river-china 

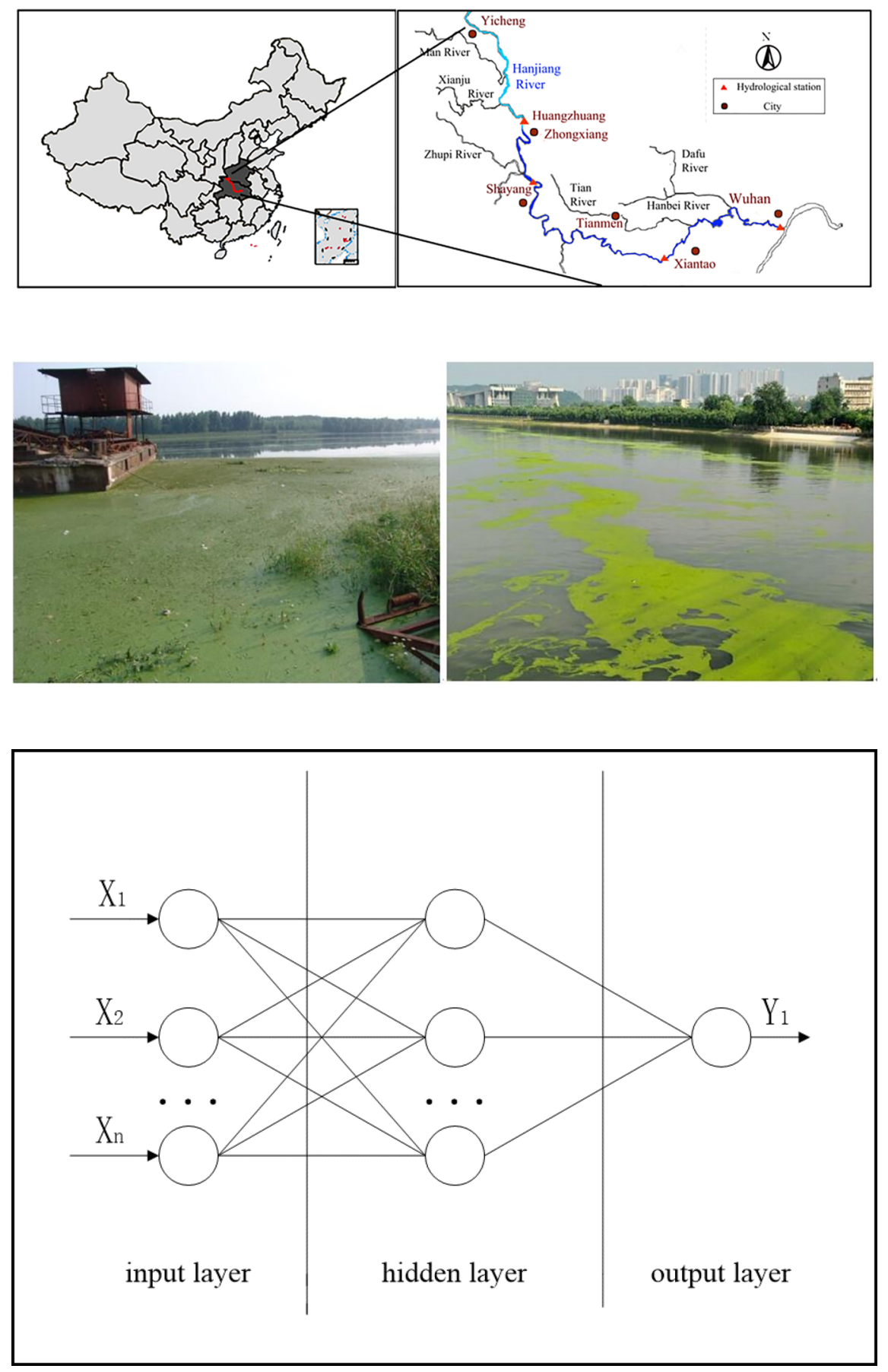


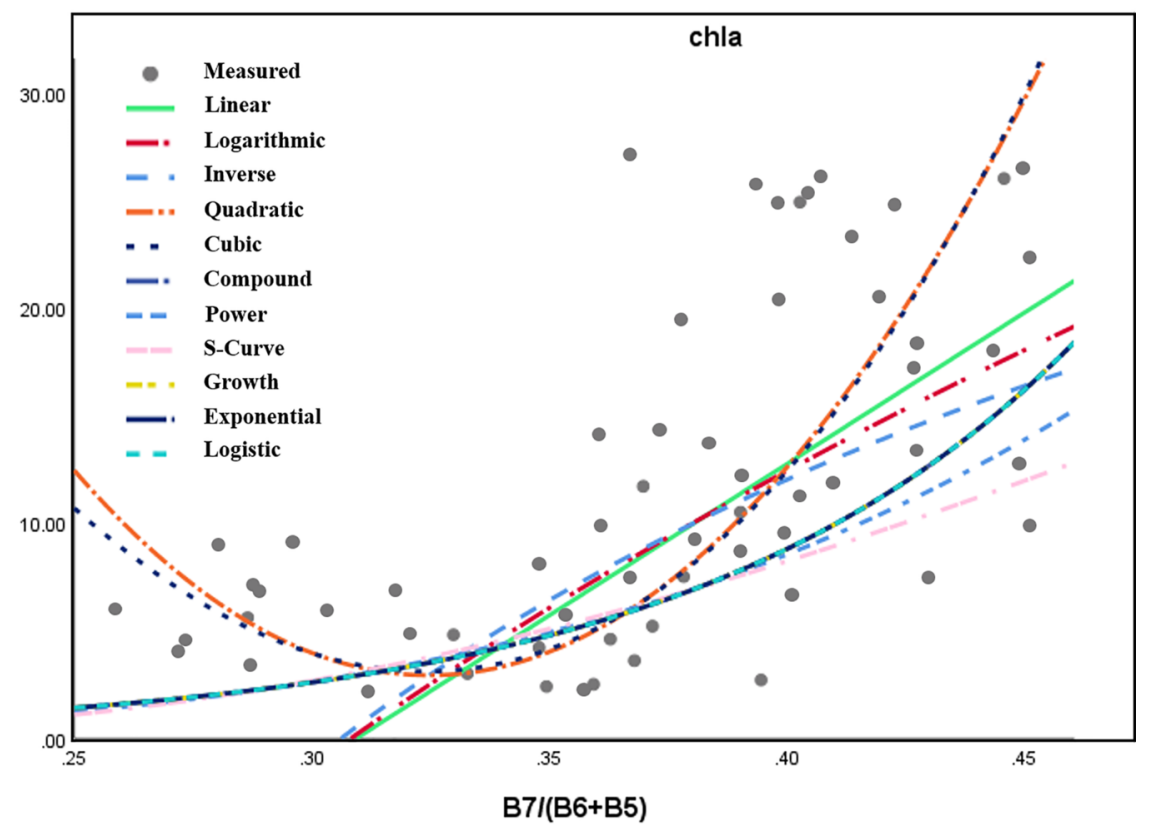

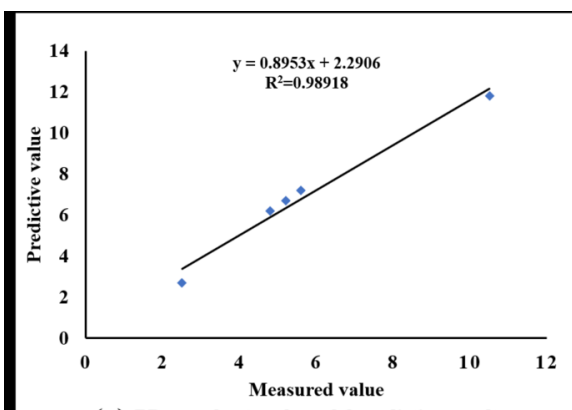

(a) BP neural network model prediction results

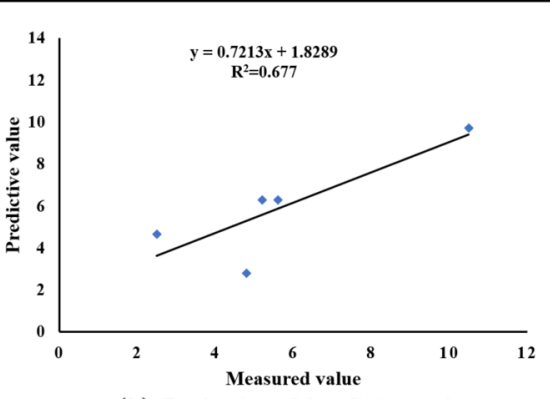

(b) Band ratio model prediction results

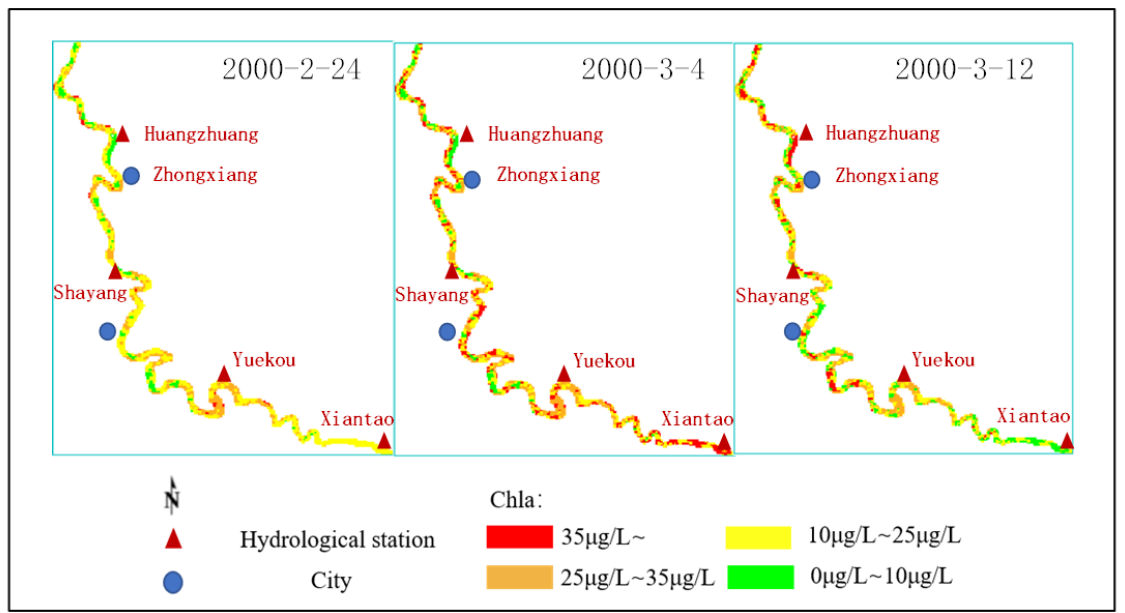




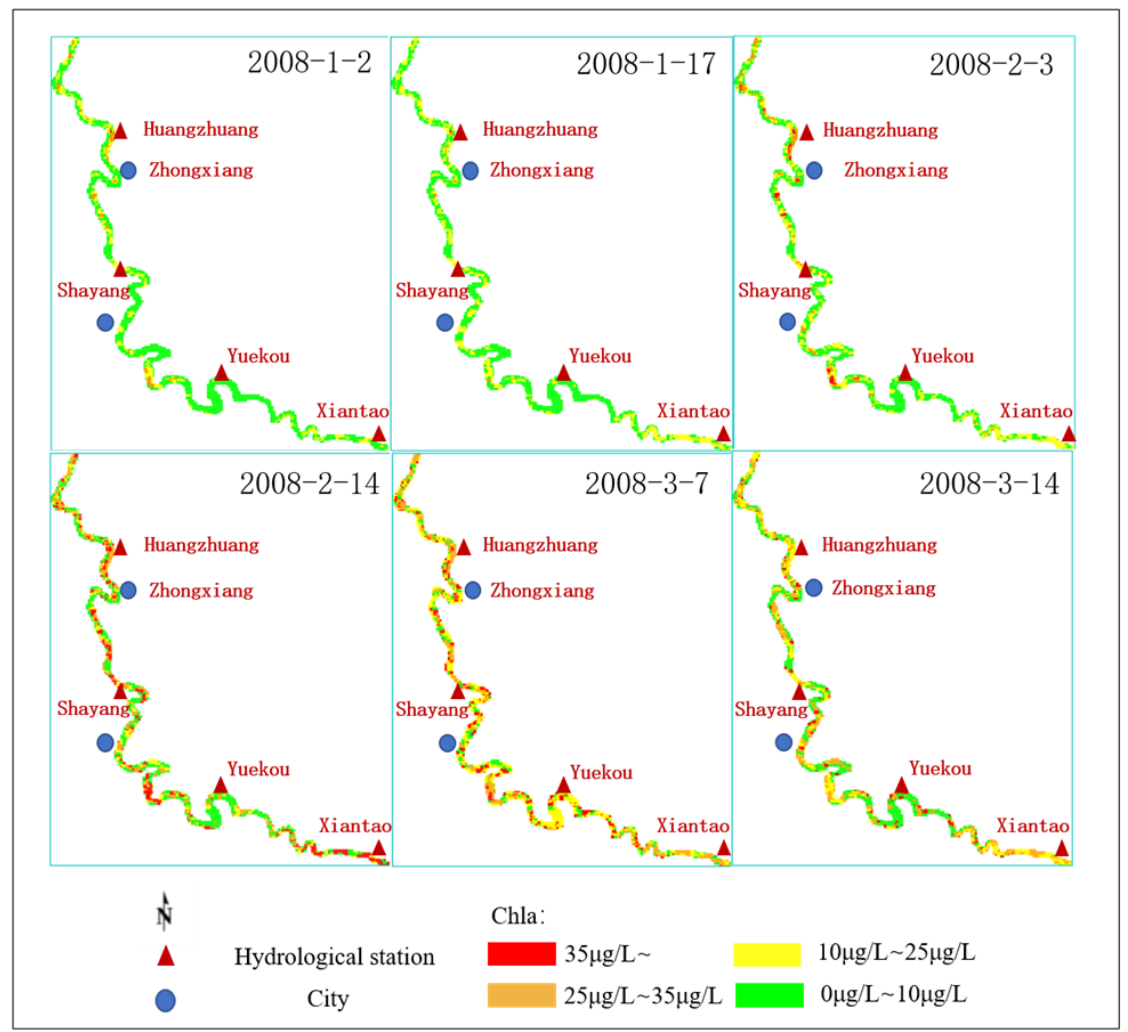



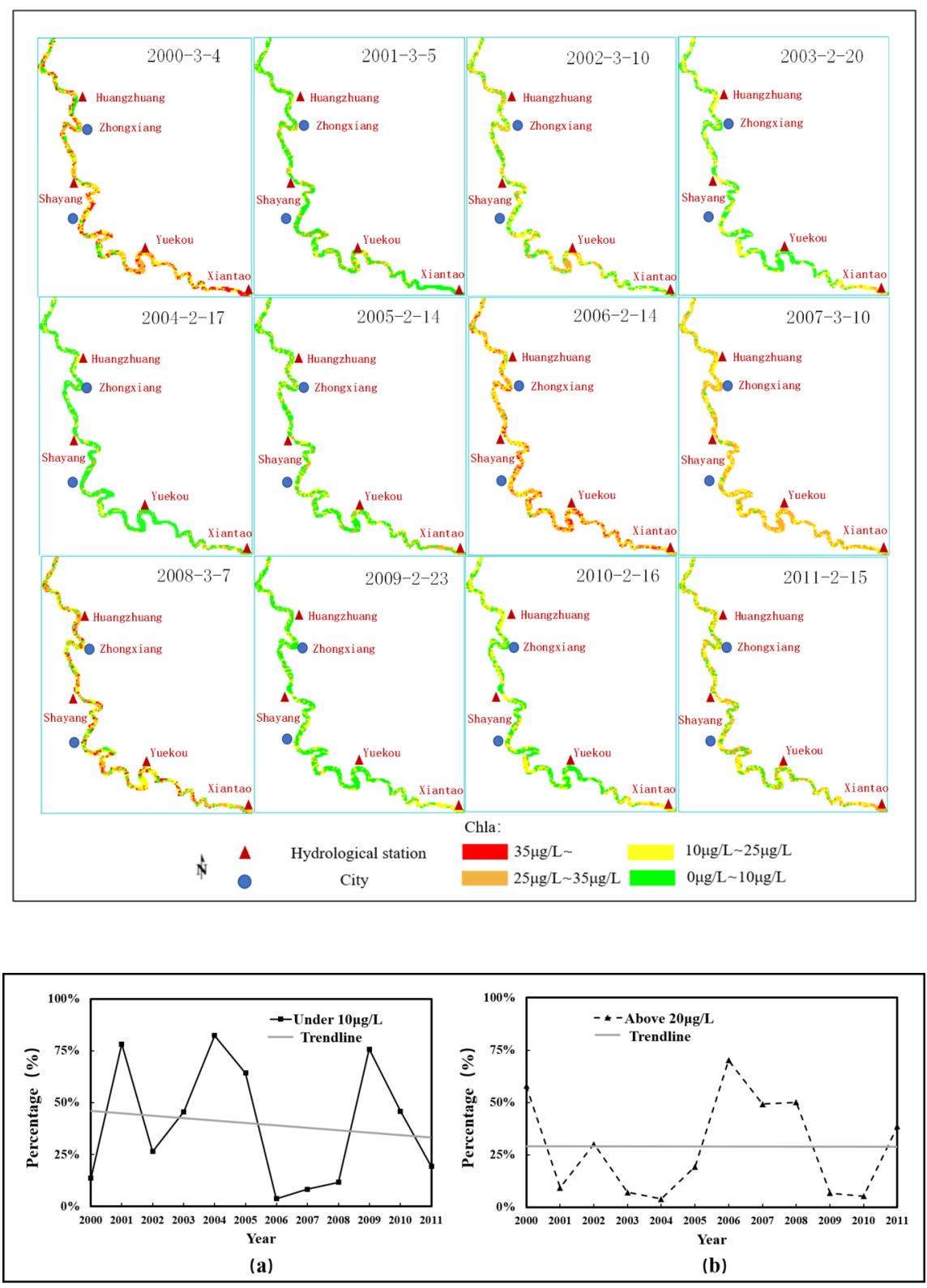

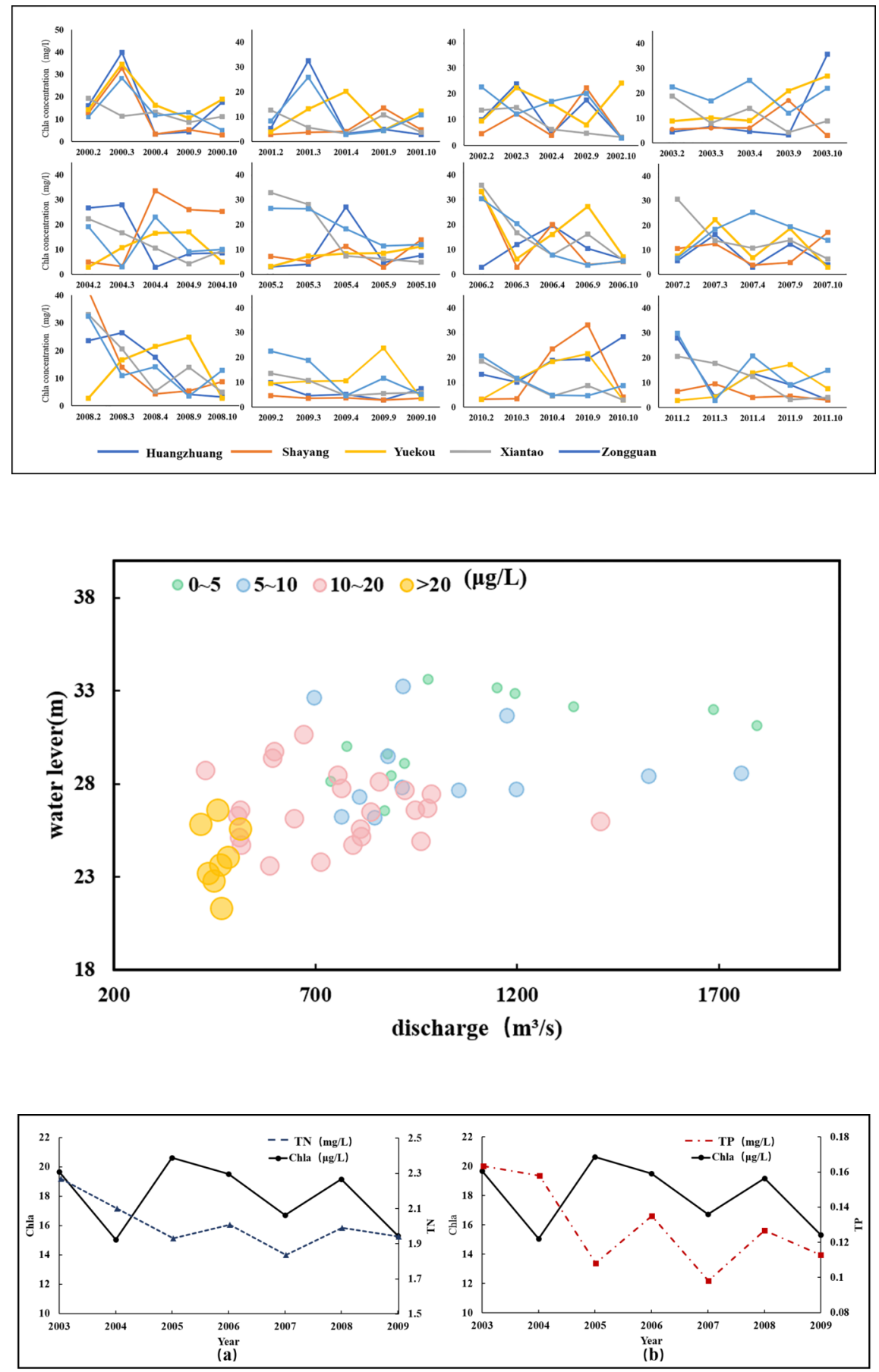